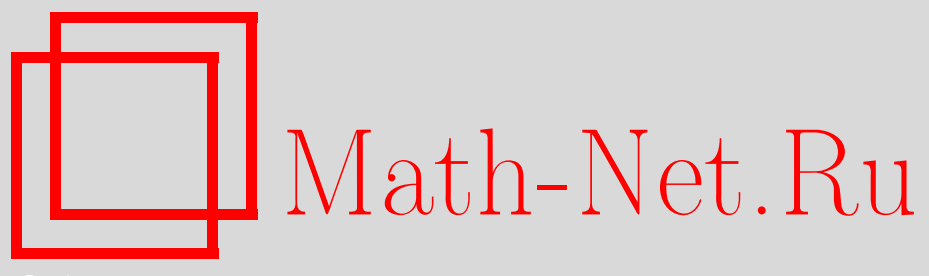

Д. В. Аносов, В. И. Арнольд, В. А. Владимиров, В. В. Козлов, Я. Г. Синай, Виктор Иосифович Юдович (некролог), УМН, 2007, том 62, выпуск 2, 165-168

DOI: https://doi.org/10.4213/rm6424

Использование Общероссийского математического портала Math-Net.Ru подразумевает, что вы прочитали и согласны с пользовательским соглашением http://www . mathnet.ru/rus/agreement

Параметры загрузки:

IP : 3.95 .254 .165

26 апреля 2023 г., 14:52:19

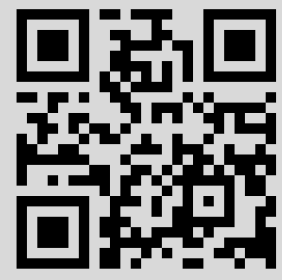




\section{Виктор Иосифович Юдович}

Виктор Иосифович Юдович родился 4 октября 1934 г. в Тбилиси, но почти вся его жизнь прошла в Ростове-на-Дону. В 1952 г. он поступил на отделение механики физико-математического факультета Ростовского государственного университета. Его научным руководителем был известный советский механик И. И. Ворович. После окончания университета в 1957 г. В.И. Юдович работал в РГУ ассистентом, в 1962 г. защитил кандидатскую диссертацию (МГУ), в 1972 г. - докторскую (ИПМ АН СССР). Решением соответствующих Советов обе работы были признаны выдающимися. В 1972 г. Виктор Иосифович возглавил кафедру вычислительной математики и математической физики РГУ; ей он руководил до конца жизни. С 1995 г. В. И. Юдович - член Национального комитета по механике, с 2002 г. - заслуженный деятель науки РФ, член Российской Национальной академии высшей школы (1995 г.). В 2000 г. ему была присуждена премия, а в 2006 г. - медаль им. акад. Г. И. Петрова. В это время Виктор Иосифович был уже тяжело болен, и 19 апреля 2006 года его не стало. Он прожил неполных 72 года.

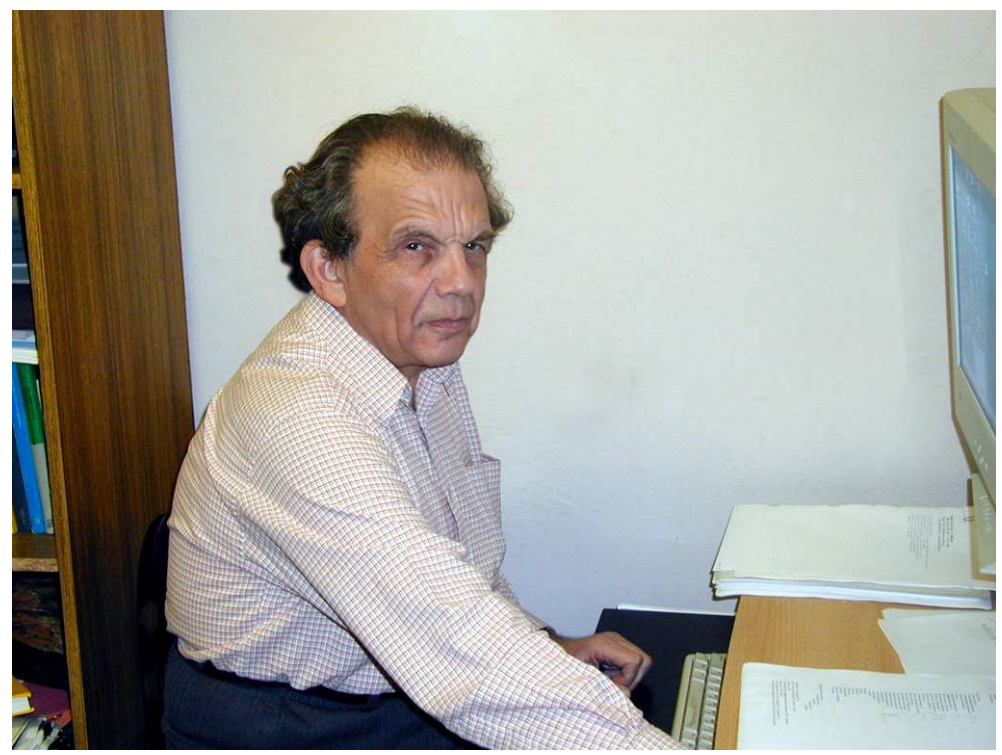

Первая научная работа В. И. Юдовича вышла в свет в 1957 г., последнюю статью он направил в печать в феврале 2006 г. За этот период он опубликовал более трехсот статей, 2 монографии и 2 учебника. В. И. был увлекающимся человеком и азартным исследователем, его научная деятельность была разнообразна, но неизменным ее центром были фундаментальные проблемы гидродинамики. Еще в начале $60-$ х годов он 
доказал глобальные теоремы существования и единственности решений нестационарных задач обтекания и протекания для плоских уравнений Эйлера; при этом были найдены важнейшие априорные оценки обобщенных и гладких решений. Идеи этих работ широко использовались в последующих исследованиях, но особую известность приобрела теорема единственности в классе полей скорости с ограниченным вихрем. Примечательно, что первое ее обобщение дал сам В. И. в 1995 г.

В 1968 г. В. И. Юдович (в соавторстве с М. Р. Уховским) впервые обосновал предельный переход при исчезающей вязкости для осесимметричных течений во всем пространстве; в 1971 г. он (совместно с Л. С. Срубщиком) построил асимптотику слаборазрывных течений при исчезаюеей вязкости. При этом был предложен весьма универсальный подход к обоснованию асимтотических разложений, основанный на методе Ньютона-Канторовича. Чуть позже, в 1974 г., В.И. заметил, что движения частиц идеальной жидкости могут иметь функционалы Ляпунова, выраженные через компоненты вихря или их производные. Таким образом был открыт "медленный коллапс" решений уравнений Эйлера, а именно были указаны частные, но довольно широкие классы течений, в которых неограниченно растет вихрь (в трехмерном случае) или его градиент (в двумерном случае). В связи с этими результатами В. И. предположил, что "медленный коллапс" происходит для “существенной" части начальных данных; по крайней мере, такие данные можно найти в окрестности любого стационарного течения.

В конце 60-х - начале 70-х годов В. И. развил теорию “первого перехода" для вязких течений. В частности, он дал обоснование метода линеаризации в задачах гидродинамической устойчивости, включая не только стационарные, но и вынужденные периодические по времени течения, а также автоколебания. Эта задача была весьма актуальна: ряд гидромехаников всерьез сомневался в применимости метода малых колебаний. ${ }^{1}$ Затем В. И. исследовал бифуркации, сопровождающие потерю устойчивости стационарных течений, в том числе, бифуркацию Пуанкаре-Андронова-Хопфа. Для этих целей он использовал эффективную комбинацию локальных аналитических и глобальных топологических методов, включая очень практичный вариант метода Ляпунова-Шмидта. В результате была установлена неединственность стационарного решения уравнений Навье-Стокса и решен (при участии И. П. Андрейчикова и С. Н. Овчинниковой) ряд конкретных задач, таких, например, как ответвление автоколебаний от плоского течения Пуазёйля и рождение вихрей Тэйлора. Комбинируя метод Ляпунова-Шмидта с длинноволновой асимптотикой, В. И. получил почти явные выражения автоколебаний, возникающих при длинноволновой неустойчивости. Одновременно он обратился к теории гравитационной конвекции и задачам вязкоупругости, где развитые им методы исследования вторичных режимов нашли новые яркие приложения. В то же время его внимание привлекли смежные задачи линейной теории. В первой половине 70-х он (в соавторстве с А. А. Есиповым) разъяснил и обосновал принцип Рэлея в теории свободной конвекции. Затем его усилия сконцентрировались на спектральной теории несамосопряженных операторов. Интерес к ней был мотивирован тем, что применение методов теории бифуркаций требует предварительного исследования нейтрального спектра оператора линеаризованной задачи, который вовсе не всегда самосопряжен. В.И. Юдович (в соавторстве Ю.С. Барковским) распространил теорию осцилляционных операторов Келлога-ГантмахераКрейна на случай несамосопряженных операторов и развил метод одномерных возмущений. Последний позволяет исследовать конечные возмущения, возникающие,

\footnotetext{
${ }^{1}$ Обсуждение этого вопроса можно найти в известной книге: С. C. Lin, The theory of hydrodynamic stability, Cambridge University Press, 1955.
} 
например, при изменении граничного условия в краевой задаче для обыкновенного дифференциального уравнения. Важным приложением этих результатов было доказательство простоты нейтрального собственного значения при потере устойчивости течением Куэтта, что позволило завершить математическую теорию вихрей Тэйлора.

В начале 80-х годов Виктор Иосифович увлекся математической теорией электрофореза. Эта теория (развитая совместно с М. Ю. Жуковым и В.Г. Бабским) получила блестящее экспериментальное подтверждение и нашла множество приложений. Во второй половине 80-х В.И. наметил масштабный план исследования переходов в задаче Куэтта-Тэйлора на основе анализа бифуркаций старших коразмерностей, возникающих при пересечении критических кривых, соответствующих различным модам неустойчивости, и приступил к его реализации вместе со своими учениками и сотрудниками. В результате были найдены новые типы колебательных движений жидкости, включая и хаотические. Тем не менее, эта задача не исчерпана и по сей день: последняя работа В. И. Юдовича на эту тему (написанная в соавторстве с С.Н. Овчинниковой) была завершена и направлена в печать уже после его смерти.

В начале 90-х годов В.И. приступил к развитию теории динамических систем с косимметрией. Косимметрией векторного поля называется всюду аннулирующая его дифференциальная 1-форма. Если эта форма точна, то косимметрия есть дифференциал интеграла движения. Принципиально новый объект возникает, когда эта форма не точна и обладает неким свойством нетривиальности (достаточно, чтобы эта 1-форма не обращалась в нуль на касательном пространстве, приложенном в особой точке поля). Введение этого понятия было мотивировано странной чертой возникновения конвекции в пористой среде, замеченной Д. В. Любимовым: оказалось, что соответствующее амплитудное уравнение имеет непрерывное семейство стационарных решений, но непрерывную группу симметрий системы обнаружить не удалось. В. И. Юдович показал, что потеря устойчивости состояния механического равновесия действительно приводит к возникновению однопараметрического семейства стационарных движений и это явление обусловлено исключительно нетривиальной косимметрией задачи.

В последнее десятилетие жизни В.И. его деятельность стала еще более разнообразной: он вводит и исследует предельные модели конвекции, в частности, модель сильно вязкой нетеплопроводной жидкости (близкими свойствами обладает вещество мантии Земли); дает новую инвариантную формулировку метода усреднения для систем с быстро осциллирующими силами и связями; исследует спектральные свойства дифференциальных операторов с периодическими коэффициентами и на этой основе решает при участии С. М. Зеньковской ряд задач о параметрическом возбуждении волн на поверхности жидкости. $\mathrm{K}$ этому можно добавить полное решение задачи Кельвина об устойчивости правильных вихревых многоугольников (полученное совместно с Л. Г. Куракиным) и своеобразную теорию устойчивости стационарных режимов протекания идеальной жидкости сквозь область (развитую совместно с А. Б. Моргулисом).

Одновременно В.И. вернулся к проблеме глобальной разрешимости, единственности и регулярности решений уравнений гидродинамики. Усовершенствуя свои результаты в этих направлениях, он выдвинул ряд новых идей и гипотез. Среди них гипотеза о связи единственности решений задач с начальными данными для уравнения Эйлера и эйлерова поля скорости и связанная с ней задача обобщения теоремы Орлича о нетипичности (в смысле категорий Бэра) непрерывного поля направлений с точкой касания различных интегральных кривых; новая идея описания движения жидкости с помощью функций и полей случайного аргумента, а также редукции 
(в смысле Рауса) уравнений гидродинамики на совместные множества уровня интегралов вихря и связи несжимаемости. Последнее направление имеет и весьма практический аспект: законы сохранения вихря автоматически выполняются для любого (даже численного!) решения редуцированных уравнений, тогда как существующие численные методы решения уравнений Эйлера не могут обеспечить выполнения всех этих законов.

K несчастью, Виктору Иосифовичу не было суждено до конца воплотить свои захватывающие планы; они остаются следующим поколениям исследователей.

Д. В. Аносов, В.И. Арнольд, В.А. Владимиров, В.В. Козлов, Я.Г. Синай 